\section{SOI: $1.1 /$ TAS DOI: $10.15863 / \mathrm{TAS}$ International Scientific Journal Theoretical \& Applied Science}

Avazkhon Talgatovich Agzamov doctoral student the Department of Finance and taxes, TSUE avazxon1973@mail.ru +99897-751-66-05

p-ISSN: 2308-4944 (print) e-ISSN: 2409-0085 (online) +99894-650-14-30

Year: 2018 Issue: 03 Volume: 59

Published: $10.03 .2018 \quad$ http://T-Science.org

SECTION 31. Economic research, finance, innovation, risk management.

\title{
ON THE ISSUE OF IDENTIFYING CURRENT TRENDS IN THE DEVELOPMENT OF TAXATION OF INDIVIDUALS IN THE REPUBLIC OF UZBEKISTAN
}

Abstract: This article examines the identification of current trends in the development of the system of taxation of individuals in the Republic of Uzbekistan. It is based on the fact that the taxation system for individuals is the driving force of the economy of any country.

Key words: tax, taxation, individuals, economics, taxpayers

Language: Russian

Citation: Agzamov AT (2018) ON THE ISSUE OF IDENTIFYING CURRENT TRENDS IN THE DEVELOPMENT OF TAXATION OF INDIVIDUALS IN THE REPUBLIC OF UZBEKISTAN. ISJ Theoretical \& Applied Science, 03 (59): 24-28.

Soi: http://s-0-i.org/1.1/TAS-03-59-6 Doi: crossef https://dx.doi.org/10.15863/TAS.2018.03.59.6

\section{К ВОПРОСУ ВЫЯВЛЕНИЯ СОВРЕМЕННЫХ ТЕНДЕНЦИЙ РАЗВИТИЯ НАЛОГООБЛОЖЕНИЯ ФИЗИЧЕСКИХ ЛИЦ В РЕСПУБЛИКЕ УЗБЕКИСТАН}

Аннотация: В данной статье рассматривается выявление текущих тенденций развития системы налогообложения физических лиц в Республике Узбекистан. Он основан на том факте, что система налогообложения физических лии является движущей силой экономики любой страны.

Ключевые слова: налог, налогообложения, физических лии, экономика, налогоплательщики

\section{Introduction}

Система налогообложения физических лиц является неотъемлемой частью любой страны, поскольку она участвует в формировании доходов государственного бюджета, в дальнейшем используемый для решения проблем того или иного региона. Налогообложение физических оказывает сильное влияние на экономику, являясь одним из самых главных инструментов ограничения или стимулирования деятельности в конкретных сферах экономики. В связи с этим сложно переоценить значимость системы налогообложения физических лиц для эффективного функционирования государства, полноценного выполнения всех поставленных перед ним задач и создания высокого качества жизни населения.

\section{Materials and Methods}

Основными тенденциями налогообложения физических лиц конца XX и начала XXI века является стремление правительств к оптимизации своих налоговых систем и минимизации государственных издержек при взимании налогов; снижению налогового бремени при помощи налоговых льгот для привлечения зарубежных инвестиций в страну и для развития новых технологий в производстве, а также поддержке малого предпринимательства; созданию взаимоувязанных и целостных систем налогов с механизмами защиты от двойного налогообложения.

В зарубежных странах с развитой рыночной экономикой доминирует прямое налогообложение с высокими прогрессивными налоговыми ставками, и с расширенной системой льгот и вычетов. В этих государствах в доходах бюджета доля прямых налогов составляет в среднем 70\%. В Узбекистане же в доходах бюджета доля прямых налогов составляет около 30\%. Уровень ставок основных бюджетообразующих налогов зарубежных стран намного превышает ставки аналогичных налогов в Узбекистане. Некоторые налоги, например, 
налог на наследство и дарение вообще отсутствуют в системе налогов Узбекистана.

Любая система налогообложения базируется на нормативных документах, в Узбекистане это Налоговый Кодекс, которая является упрощенной и доступной для каждого налогоплательщика и включает в себя все нормативные документы касающиеся вопросы налогообложения.

Эффективная налоговая политика государства в области налогообложения физических лиц выступает одной из главных форм воздействия на общее финансовое состояние населения, является главным фактором развития государства, укрепления его позиций на международном уровне. В свою очередь она не может быть осуществлена без использования эффективных инструментов налоговой политики. Одним из главных таких инструментов выступает оптимизация системы налогообложения физических лиц.

Налоги выражают обязанность физических лиц, получающих доходы, участвовать в формировании государственных финансовых ресурсов. Поэтому налоги с физических лиц выступают важнейшим звеном финансовой политики государства в современных условиях.

В соответствии с Налоговым Кодексом Республики Узбекистан налоги - это установленные обязательные денежные платежи в бюджет, взимаемые в определенных размерах, носящие регулярный, безвозвратный и безвозмездный характер. Под другими обязательными платежами понимаются установленные законодательством обязательные денежные платежи в государственные целевые фонды, таможенные платежи, а также сборы, государственная пошлина, уплата которых является одним из условий совершения в отношении плательщиков уполномоченными органами и должностными лицами юридически значимых действий, включая предоставление определенных прав или выдачу лицензий и иных разрешительных документов[1].

В направлении 3.2. в пунктах 13-16 Государственной программы по реализации Стратегии действий по пяти приоритетным направлениям развития Республики Узбекистан в 2017-2021 годах в «Год диалога с народом и интересов человека» поручено «снижение налогового бремени и продолжение политики упрощения системы налогообложения, совершенствование налогового администрирования и расширение соответствующих стимулирующих мер»[2].

В связи с принятием Указа Президента №3454 от 29 декабря 2017 года “Об основных макроэкономических показателях и о параметрах Государственного бюджета Республики Узбекистан за 2018 год” и “Основных направлений налоговой и бюджетной политики государства в 2018 году” был принят закон №454 “О применении изменений и дополнений в отдельные законодательные акты Республики Узбекистан".

В связи с этим немаловажным является изучение внесенных изменений в систему налогообложения физических лиц в 2018 году по сравнению с 2017 годом ( таблица-1).

\section{СРАВНЕНИЕ}

Таблица-1

основных ставок налогов и обязательных платежей физических лиц в Республике Узбекистан за 2017-2018 годы ${ }^{1}$

\begin{tabular}{|c|c|c|c|c|}
\hline № & Виды налогов и обязательных платежей & 2017 г. & 2018 г. & Изменения \\
\hline 1. & Подоходный налог с физических лиц & \multicolumn{3}{|c|}{ (отчис-я на ИНПС повышается с $1 \%$ на $2 \%$ ) } \\
\hline & $\begin{array}{l}\text { До } 1 \text { размера минимальной месячной заработной } \\
\text { платы (ММЗП) }\end{array}$ & $0 \%$ & $0 \%$ & без изменений \\
\hline & От 1 размера (+1 сум) до 5 размеров ММЗП & $7,5 \%$ & $7,5 \%$ & без изменений \\
\hline & От 5 размеров $(+1$ сум $)$ до 10 размеров ММЗП & $17 \%$ & $16,5 \%$ & (снизился на 0,5\%) \\
\hline & От 10 размеров (+1сум) ММЗП и больше & $23 \%$ & $22,5 \%$ & (снизился на 0,5\%) \\
\hline 2. & $\begin{array}{l}\text { Налог на доходы резидентов Республики } \\
\text { Узбекистан полученных в виде девидендов и }\end{array}$ & $10 \%$ & $10 \%$ & без изменений \\
\hline
\end{tabular}

1 Составлено автором на основе Постановления Президента Республики Узбекистан «О прогнозе основных макроэкономических показателей и параметрах государственного бюджета Республики Узбекистан на 2017 год» от 27 декабря 2016 года № ППП-2699 и Указа Президента №3454 от 29 декабря 2017 года “Об основных макроэкономических показателях и о параметрах государственного бюджета Республики Узбекистан за 2018 год” и “Основных направлений налоговой и бюджетной политики государства в 2018 году”. 


\begin{tabular}{|c|c|c|c|c|c|c|}
\hline Impact Factor: & $\begin{array}{l}\text { ISRA (India) } \\
\text { ISI (Dubai, UAE } \\
\text { GIF (Australia) } \\
\text { JIF }\end{array}$ & $\begin{array}{r}=1.344 \\
=0.829 \\
=0.564 \\
=1.500\end{array}$ & $\begin{array}{l}\text { SIS (USA) } \\
\text { PИНЦ (Russia) } \\
\text { ESJI (KZ) } \\
\text { SJIF (Morocco) }\end{array}$ & $\begin{array}{l}=0.912 \\
=0.207 \\
=4.102 \\
=2.031\end{array}$ & $\begin{array}{l}\text { ICV (Poland) } \\
\text { PIF (India) } \\
\text { IBI (India) }\end{array}$ & $\begin{array}{l}=6.630 \\
=1.940 \\
=4.260\end{array}$ \\
\hline
\end{tabular}

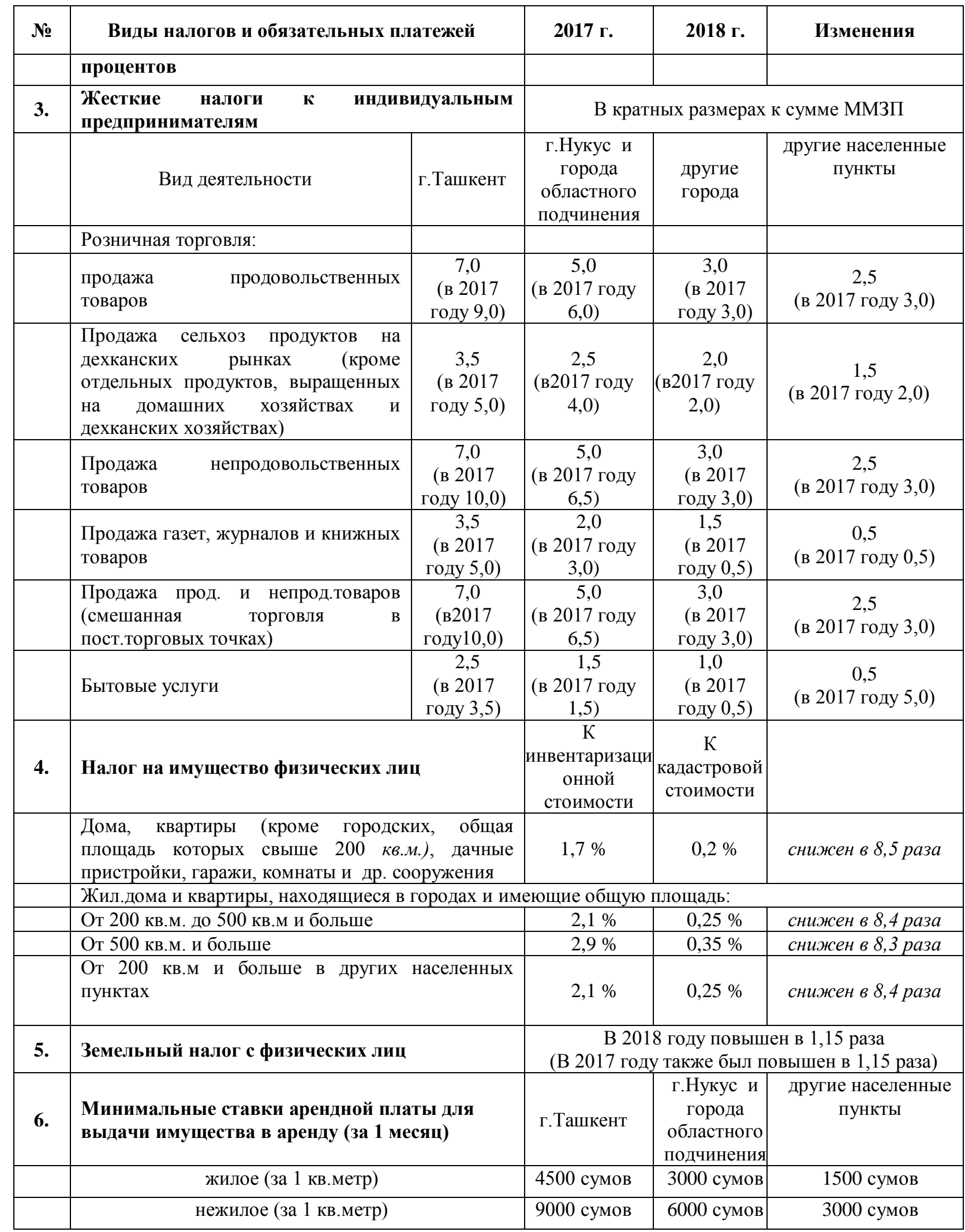

Кроме того, в нашей стране проводятся ряд реформ по совершенствованию налогового контроля. В частности с января 2018 года согласно Указу Президента Республики
Узбекистан от 18 июля 2017 года «О мерах по коренному совершенствованию налогового администрирования, повышению собираемости налогов и других обязательных платежей»[3] 
вводится современная форма налогового контроля - налоговый мониторинг. В соответствии с данным документом налоговый мониторинг предусматривает расширенный информационный обмен между налоговыми органами и добросовестными налогоплательщиками с предоставлением им всестороннего содействия в решении текущих вопросов налогообложения. В области обеспечения в полном объеме поступления налогов и других обязательных платежей в Государственный бюджет Республики Узбекистан, государственные целевые фонды и внебюджетные фонды в соответствии с Налоговым кодексом Республики Узбекистан и иными актами законодательства осуществляется камеральный контроль на основе изучения и анализа представленной в установленном порядке налогоплательщиками финансовой и налоговой отчетности, а также других документов о деятельности налогоплательщиков, имеющихся в органах государственной налоговой службы.

За годы независимости экономика Узбекистана прошла несколько этапов, в том числе этап макроэкономической стабильности. В достижении высоких темпов развития экономики велика роль реформ, проводимых в налоговой системе.

Основной целью проводимых реформ в стране является формирование эффективной налоговой системы, отвечающей требованиям рыночной экономики. Об этом говорит и Президент страны Ш.М. Мирзиёев «Сегодня задача каждого из нас, и прежде всего руководителей органов государственного управления, на основе критического анализа положения дел в соответствующих сферах и отраслях ответственно обеспечить реализацию возложенных на нас задач». [4]

Вместе с тем важно помнить, что экономика нашей страны связана с экономикой других стран, что является результатом процессов глобализации. Между тем глобализация мировой экономики привела к тому, что мировое производство стало смещаться в страны с низкими издержками, это в свою очередь обусловило рост доходов в странах-экспортерах. В результате избыточные сбережения стали дисбалансом на мировом денежном рынке, вследствие чего усиливаются различия между развитыми и развивающимися странами.

Активное вовлечение имеющихся резервов и возможностей в обеспечение устойчивого экономического роста зависит также и от модернизации налоговой политики. Эффективная реализация модернизации налоговой системы как важнейшего направления системы государственного регулирования экономики является одним из ключевых факторов, способствующих экономическому развитию.

В современных условиях перехода к новым отношениям, когда происходит широкомасштабная реализация реформ в различных сферах социально-экономической жизни страны модернизация налоговой системы становится наиболее важным фактором. В этом процессе исключительное значение имеет реализация перемен в различных векторах реформы системы налогообложения Республики Узбекистан, которые происходят наиболее интенсивными темпами. Следовательно, под влиянием этого реформационного процесса существенному изменению подвергается экономическая среда, налоговая и социальная политика страны.

\section{Conclusion}

Налоговая политика Узбекистана, основанная на модернизации всех векторов налоговой реформы, которая вступает, в фазу эффективной реализации, требует рассмотреть ее в свете дальнейшего совершенствования с учетом современных факторов. К тому же постоянно растущее значение этой политики в деле улучшения жизненного уровня населения требует принять неотложные меры. Именно эффективное формирование модернизации налоговой системы должно быть устойчивым гарантом эффективного и реального экономического роста в стране.

Осуществление модернизации налоговой системы Республики Узбекистан является актуальной задачей, стоящей сегодня перед всем обществом. То место, которое займет страна в системе международного разделения труда, а значит и доходы, и уровень благосостояния населения, и культурное развитие и будущее страны в ближайшей и отдаленной перспективе, безусловно, зависит от успеха модернизации и диверсификации налоговой системы.

Таким образом, успешная реализация предлагаемых мер по повышению роли эффективных мер налоговой политики в обеспечении модернизации налоговой системы и сохранение устойчивого экономического роста позволит повысить эффективность деятельности налоговых органов.

В процессе рассмотрения основных направлений налоговой политики в сфере уплаты налогов физическими лицами в целях эффективного осуществления данного процесса необходимо:

- обеспечение исполнения нормативно-правовых документов всеми субъектами процесса налогообложения физических лиц;

- проведение мероприятий по обеспечению соблюдения налогового законодательства; 


\begin{tabular}{|c|c|c|c|c|c|c|}
\hline Impact Factor: & $\begin{array}{l}\text { ISRA (India) } \\
\text { ISI (Dubai, UAE } \\
\text { GIF (Australia) } \\
\text { JIF }\end{array}$ & $\begin{array}{l}=1.344 \\
=0.829 \\
=0.564 \\
=1.500\end{array}$ & $\begin{array}{l}\text { SIS (USA) } \\
\text { PИНЦ (Russia) } \\
\text { ESJI (KZ) } \\
\text { SJIF (Morocco) }\end{array}$ & $\begin{array}{l}=0.912 \\
=0.207 \\
=4.102 \\
=2.031\end{array}$ & $\begin{array}{l}\text { ICV (Poland) } \\
\text { PIF (India) } \\
\text { IBI (India) }\end{array}$ & $\begin{array}{l}=6.630 \\
=1.940 \\
=4.260\end{array}$ \\
\hline
\end{tabular}

- проводить мероприятия по повышению налоговой грамотности налогоплательщиков, с активным использованием информационнокоммуникационных технологий.

Для совершенствования налогообложения физических лиц в Республике Узбекистан целесообразно:

- ввести необлагаемый налогом на доходы физических лиц минимум равный величине прожиточного минимума;

- способность повышению налоговой культуры через раскрытие информации о направлениях использования уплачиваемых физическими лицами налогов, о порядке предоставления социальных и имущественных вычетов;
- пересмотреть подходы к налоговым ставкам по налогу на доходы, осуществлять переход к прогрессивной шкале налогообложения;

- изменить порядок предоставления социальных и имущественных налоговых вычетов.

Осуществляя совершенствование системы налогообложения физических лиц, все же необходимо помнить о том, что налог на доходы физических лиц является мощным рычагом воздействия не только на пополнение доходов бюджетов разных уровней, но и на социальную составляющую подоходного налогообложения физических лиц - регулирование уровня жизни населения.

\section{References:}

1. (2007) Nalogovyy kodeks Respubliki Uzbekistan, st. 12. (Sobranie zakonodatel'stva Respubliki Uzbekistan, 2007)

2. (2017) Prilozhenie №8 k Ukazu Prezidenta Respubliki Uzbekistan ot 7 fevralya 2017 goda № UP-4947. Strategiya deystviy po pyati prioritetnym napravleniyam razvitiya Respubliki Uzbekistan v 2017-2021 godakh

3. (2017) Ukaz Prezidenta Respubliki Uzbekistan ot 18 iyulya 2017 goda «O merakh po korennomu sovershenstvovaniyu nalogovogo administrirovaniya, povysheniyu sobiraemosti nalogov i drugikh obyazatel'nykh platezhey»

4. Sh.M. Mirzieev (2017) Kriticheskiy analiz, zhestkaya distsiplina i personal'naya otvetstvennost' dolzhny stat' povsednevnoy normoy v deyatel'nosti kazhdogo rukovoditelya» «Uzbekistan» 17.01.2017 g.

5. Adashev A. U., Askaraliev A. (2017) SOVREMENNYE PODKhODY K POKAZATELYaM I TsENNOSTYaM EKONOMIChESKOGO RAZVITIYa //Teoriya i praktika sovremennoy nauki. - 2017. - №. 2. - p. 28-30.
6. Shakirova G. Sh. (2014) Povyshenie effektivnosti korporativnogo upravleniya na predpriyatiyakh $\mathrm{v}$ usloviyakh modernizatsii ekonomiki //Molodoy uchenyy. - 2014. - №. 8. - p. 635-636.

7. Shakirova G. Sh. (2015) Nekotorye voprosy sovershenstvovaniya korporativnogo upravleniya v Uzbekistane //Molodoy uchenyy. - 2015. - №. 10. - p. 848-850.

8. Shakirova G. Sh. (2016) Motivatsiya truda rabotnikov v sfere deyatel'nosti malogo biznesa i chastnogo predprinimatel'stva //Molodoy uchenyy. - 2016. - №. 11. - p. 1074-1076.

9. Shakirova G. Sh. (2017) MILLIY IKTISODIET TARAKKIETIDA KhORIZhIY INVESTITsIYaLARNING Y̆RNI//Nauchnoe znanie sovremennosti. - 2017. - №. 4. - p. 405407.

10. Ismatov R. O., et al. (2016) Povyshenie effektivnosti upravleniya po privlecheniyu investitsiy $\mathrm{v}$ regional'nuyu ekonomiku //Molodoy uchenyy. - 2016. - №. 11. - p. 767769. 